\title{
Perdón, restitución y teatro musical: Antonio de Zamora y su visión poético-musical de los sublevados españoles durante la Guerra de Sucesión
}

\section{Forgiveness, restitution and musical theatre: Antonio de Zamora and his poetic-musical vision of Spanish rebels during the War of the Spanish Succession}

\author{
Jordi Bermejo Gregorio \\ j.bermejo.gregorio@gmail.com
}

Universitat de Barcelona

Resumen: Este trabajo estudia el discurso de Antonio de Zamora sobre el arrepentimiento y restitución de la lealtad hacia Felipe V dirigido a los sublevados españoles durante la Guerra de Sucesión. Se comprobará la importancia propagandística y retórica que, para ello, adquirieron las formas poético-musicales y escénicamente espectaculares de las fiestas reales -especialmente en el caso de la zarzuela Viento es la dicha de amor (1708)..

Palabras clave: zarzuela barroca, Antonio de Zamora, Guerra de Sucesión, Felipe V, bando austracista.

\begin{abstract}
This work studies the speech of Antonio de Zamora about the remorse and restitution of the loyalty towards Philip V directed to the Spanish rebels during the War of Succession. It will prove that the propagandistic and rhetorical importance that the poetic-musical and spectacularly forms of palatial dramas acquired to send out that political message -especially in the case of zarzuela Viento es la dicha de amor (1708).
\end{abstract}

Keywords: baroque zarzuela, Antonio de Zamora, War of the Spanish Succession, Philip V, Austrian side. 


\section{Jordi Bermejo Gregorio. Perdón, restitución y teatro musical: Antonio de Zamora y su visión poético-musical de los sublevados españoles durante la Guerra de Sucesión}

\section{Introducción}

La concepción de los reinos de la Corona de Aragón que tuvo el dramaturgo madrileño Antonio de Zamora (1665-1727) durante la Guerra de Sucesión española estuvo formada, como se verá, por la excepcionalidad circunstancial, pero basada en los principios políticos que mantenían el orden de la sociedad española de finales del siglo XVII. La percepción del conflicto que tuvo este poeta, encargado de gran parte de las fiestas y actos públicos en los últimos años de Carlos II, era mucho más compleja que la visión de enemigos o aliados. Dramaturgo de índole política -como Francisco Bances Candamo-, Zamora recibió a Felipe V como el legítimo rey por testamento del último Austria. Esta visión condicionaría la percepción de las causas del conflicto y, sobre todo, sentaría las bases propagandísticas y retóricas sobre las que el madrileño construiría la defensa de la monarquía de los Borbones. La vivencia propia de la ocupación austracista de la capital de 1706 -expuesta en el romance heroico Epinicio métrico, del mismo año- y el contacto que antes de la guerra tuvo con algunos nobles sublevados serían aprovechados por el dramaturgo como recursos simbólicos -e incluso alegóricos- para la confección del discurso expositivo de los súbditos rebelados a su rey. Todo ello lo desarrollará en las formas poético-musicales y escénicamente espectaculares de las fiestas reales, como es el caso de la zarzuela Viento es la dicha de amor (1708).

\section{Concepto y percepción del pactismo constitucional de la Corona de Aragón por Antonio}

\section{de Zamora}

En este aspecto es más que sintomático y trascendente para lo que vamos a tratar la concepción jurídica y política de realidad foral que Zamora tenía de los reinos de la Corona de Aragón antes de la guerra. En la loa del auto sacramental La honda de David, titulada Los reinos (1698) ${ }^{1}$, el dramaturgo madrileño presenta al personaje alegórico de Aragón, entre otros -tales como Castilla, Portugal, Holanda, la Fe o la Penitencia-, para que ayude a argumentar a favor de la Iglesia y que evidencie el error de la Herejía sobre el sacramento eucarístico. Pero lo curioso de esta loa es la conclusión, una vez derrotada dialécticamente esta última:

Celo $\quad$ Con un auto que me ofrece
- La honda de David-
el ingenio para hacerse
de Maredit ${ }^{2}$ en la corte,

1 El auto sacramental La honda de David fue estrenado por la compañía de Juan de Cárdenas el 29 de mayo de 1698 en el palacio Aceca de Toledo. Después pasó a Madrid, donde fue representado por la misma compañía en el corral de la Cruz del 21 de julio al 7 de agosto (Martín Martínez 2003: 43).

2 Maredit: 'Madrid'. Covarrubias dice que la etimología de la ciudad «se tiene por más cierto ser nombre arábigo» 


\section{Jordi Bermejo Gregorio. Perdón, restitución y teatro musical: Antonio de Zamora y su visión poético-musical de los sublevados españoles durante la Guerra de Sucesión}

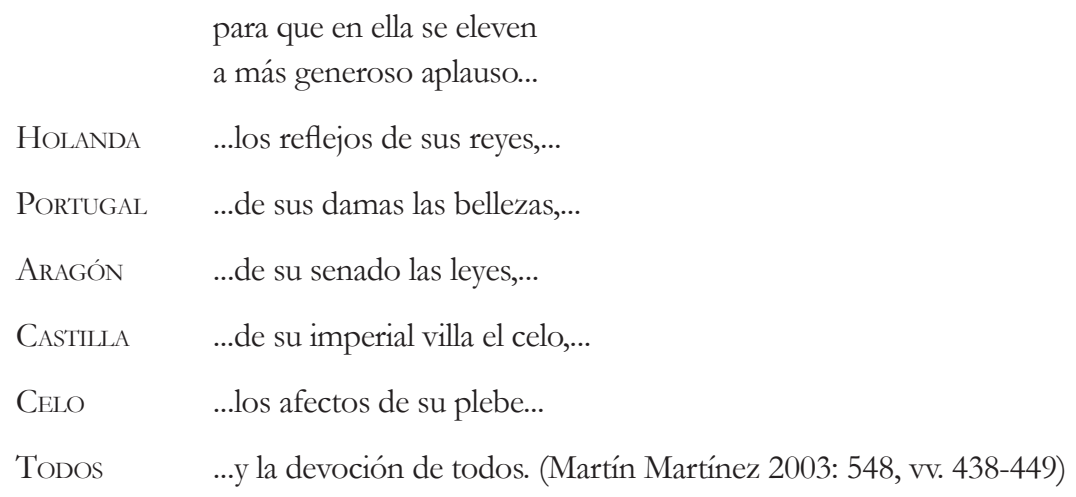

Como se ve, en Madrid han de congregarse todas las cualidades que definen la concepción católica de la monarquía española -a la que el autor cantará seguidamente con el auto sacramental-. En ese aspecto, Zamora reconoce en Aragón mucho más que una simple dimensión territorial. Gracias al celo católico y lealtad a la divina voluntad de Dios, los aragoneses pueden celebrar y disfrutar de las leyes de su senado, en clarísima alusión al pactismo y constitucionalismo foral de cada reino, productos de la tradición y evolución política e histórica de los reinos peninsulares desde los Reyes Católicos.

Como se ve, Zamora concibe que la realidad política española es inherente a la Monarquía compuesta de los reinos que, eso sí, están gobernados por un solo rey y, todo lo anterior, por una sola fe. Por ello, no diferencia en el trato entre territorios, pues para él todos son tierra española y católica. Incluso, en el entremés de Los apodos (1704), Zamora presenta a un soldado -si bien de forma cómica, como manda el género- que había venido de luchar por Felipe $\mathrm{V}$ en la campaña militar italiana de la Guerra de Sucesión -que estaba teniendo lugar en el momento del estreno-, como defensor de la ciudad de Girona en los asedios que el ejército francés hizo durante la Guerra de los Nueve Años (que enfrentó entre 1688 y 1697 a Francia contra la Gran Alianza ${ }^{3}$ ), y que incluso perdió un ojo por expulsar al extranjero invasor de la ciudad catalana ${ }^{4}$.

que significa «madre del saber, por estar allí las escuelas de ciencias en tiempo de los moros» (Covarrubias 1611: 532).

3 Exactamente, la Gran Alianza estaba formada por: España, Austria, Baviera, Brandeburgo, el Sacro Imperio Romano Germánico, Inglaterra, los Países Bajos, el Palatinado, Portugal, Sajonia y Suecia.

$4 \mathrm{Al}$ inicio del entremés, el soldado se queja de que don Longinos se ría de él porque dice que todas sus gloriosas heridas son artificio de producido por unos juanetes:

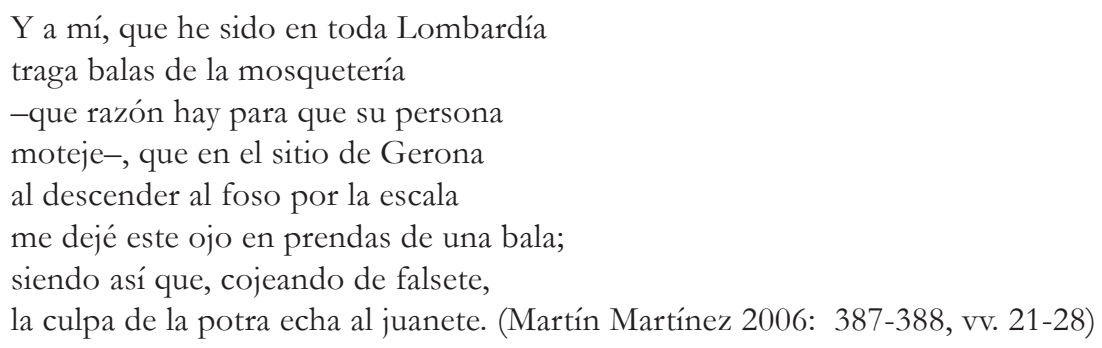




\section{Jordi Bermejo Gregorio. Perdón, restitución y teatro musical: Antonio de Zamora y su visión}

poético-musical de los sublevados españoles durante la Guerra de Sucesión

La base ideológica de esta percepción de Zamora es análoga al pensamiento político español de todo el siglo XVII. Incluso prorrogable para muchos de los partidarios de Felipe V. Es inmensamente enriquecedora la concepción que Pedro Portocarrero (1640-1708), sobrino del cardenal y político del mismo apellido, expresó en el tratado político Teatro monárquico de España (1700), pensado como guía para el correcto gobierno del nuevo rey de origen francés:

Las leyes son el alma de las repúblicas. Quien da ser a este alma es el príncipe. Si falta la ley muere la república, asólanse las ciudades y piérdese el imperio (...). La ley es el fundamento de la verdadera libertad, el origen de toda equidad, la que da la seguridad a la vida, destierra el vicio, da terror al malo y seguridad al bueno (Sanz Ayán 1998: 210).

Portocarrero hace hincapié en las leyes -aunque acondicionadas a las singularidades de cada reino, como era el caso de España $a^{5}$ como medio para sostener en la justicia y el orden la mudable naturaleza humana ${ }^{6}$, pero de igual manera exige al rey que sea no solamente garante de esas leyes ${ }^{7}$, sino que se implique activamente en su cumplimiento: «nada da más firmeza a las leyes como que sea el príncipe el primero que a ellas se arregle. Porque a su ejemplo los vasallos hacen lo mismo» (Sanz Ayán 1998: 212). Como leyes máximas de los distintos reinos, estas palabras pueden aplicarse al respeto del pactismo y constitucionalismo de los distintos reinos de la Corona de Aragón -tal como lo concebía Zamora-.

Pues bien, Felipe V juró las constituciones catalanas el 4 de octubre de 1701 y abrió las Cortes del Principado. Con ellas se ratificó que «en Cataluña quien hace las leyes es el rey con la corte» (citado desde Albareda Salvadó 2010: 79), y en estas «se disponen justísimas leyes con las cuales se asegura la justicia de los reyes y la obediencia de los vasallos» (citado desde Albareda Salvadó 2010: 81). Estas palabras parecen ecos de aquellas de Portocarrero, las que aludía a que las leyes son «las áncoras firmes del imperio», según apunta Carmen Sanz Ayán (1998: LXIX). Continuaron

5 Destaca Portocarrero que «de gran beneficio gozan las monarquías que tienen leyes justas y adecuadas a sus naturales usos y costumbres» (Sanz Ayán 1998: 213). Esto, interpretándolo como consejo al futuro reinado de Felipe $\mathrm{V}$, tiene una aplicación política directa e inconfundible para el devenir de España en respeto y con respecto a sus leyes: «¿qué monarquía del orbe con más razón puede blasonar de justa en su gobierno que la de España? Aunque esta proposición tenga contra sí las mordaces lenguas de tantos envidiosos émulos de su grandeza, ¿a qué fatigas de sus tumultuosos juicios han solicitado oscurecer los rayos del más lúcido sol de la tierra, como lo han sido sus grandes monarcas que, atentos siempre a la observancia de las leyes, sin querer singularizarse en ellas, han dominado gran parte del orbe y mantenido en él los dominios heredados y adquiridos por la espada, contra las más bastas potencias de Europa y Asia?» (Sanz Ayán 1998: 213-214).

6 Con estas palabras argumenta Portocarrero la necesidad de las leyes: «todos los hombres y toda criatura por su naturaleza son flexibles y mudables, porque todo se formó de la nada y por esto el hombre es mudable. Y a lo bueno y a lo malo, y para que viva con rectitud apartándose de lo malo y se acostumbre y ejercite en actos virtuosos es precisa la ley, que no solo quite el pecado sino que arranque su raíz» (Sanz Ayán 1998: 208-209).

7 «Pertenece la protección de la ley al príncipe o magistrado supremo, que sobre ellas debe velar de día y de noche, no dando lugar a la más mínima alteración» (Sanz Ayán 1998: 211). 
Jordi Bermejo Gregorio. Perdón, restitución y teatro musical: Antonio de Zamora y su visión poético-musical de los sublevados españoles durante la Guerra de Sucesión

jurándose las constituciones en Aragón el 26 de abril, aunque en este caso solo la reina, pues el rey había partido desde Barcelona rumbo a las posesiones italianas. No se convocaron cortes ni en Valencia ni en Mallorca.

Pero, como se sabe, desde Catalunya se inició la rebelión a Felipe V, oficializándose con el Pacto de Génova (junio de 1705). A pesar de las consideraciones que tanto el mismo rey como Luis XIV habían mostrado en relación con el respeto de los fueros y de sus cortes ${ }^{8}$, los actores internacionales empezaron a jugar sus cartas con tal de desestabilizar el segundo reino Borbón?. Sea producido interesadamente por los enemigos europeos de los Borbones, o no, el hecho es que en Catalunya la francofobia latente en los catalanes junto con el miedo a «un gobierno de corte francés y, por lo tanto, más centralizado y autoritario que el de los Austrias» (Castro 2004: 121), y junto con la nefasta administración y gobierno del virrey Velasco - de perfil peligroso para el pactismo constituciona ${ }^{10}$ - motivó un anhelo rupturista con el nuevo rey. Estos tres motivos empezaron a propagar «la fidelidad de amplios sectores de los grupos dominantes hacia la casa de Austria, cuyo "dominio suave" deseaban mantener» (Castro 2004: 121). En el otoño de 1705 la sublevación se efectuaba en Catalunya, extendiéndose rápidamente al resto de los territorios de la Corona de Aragón, que, en su gran mayoría, consideraron como rey al archiduque Carlos.

De esta manera el contrato entre el soberano y los súbditos y vasallos había sido roto por voluntad de estos últimos por intereses o causas ajenas a las eminentemente legales. Entonces, y desde el punto de vista de la autoridad de Felipe $\mathrm{V}$ y sus leales, debe hacerse prevalecer la ley sin relajación alguna ni la más mínima alteración, «aun en lo más ligero, porque de lo leve se pasa con facilidad a lo más» (Sanz Ayán 1998: 211). La consecuencia ha de ser la reprensión y corrección a la fuerza para que los sublevados vuelvan a la cordura y al servicio del único rey posible, heredero de Carlos II. Esta idea tan básica y común de tratamiento y corrección del sedicioso estaba muy presente en Pedro de Portocarrero, tal como lo explica Carmen Sanz Ayán: «cuando estos [los vasallos] rompen el pacto, está justificado despojarles de sus libertades y, es más, haría mal en dejárselas, "porque por derecho han decaído en ellas y no tiene el príncipe obligación de reintegrarlas"» (Sanz Ayán 1998: LXXVI-LXXVII). Igualmente, muchos e importantes eran los que aconsejaron al rey que meditase las medidas de castigo, ante la trascendencia de estas ${ }^{11}$.

\footnotetext{
8 Baudrillart lo expresó de la siguiente manera: «"vuestra paciencia era necesaria”, dijo Luis XIV, menos absoluto en los estados de su nieto que en los propios. Había que hacer ver a aquellos pueblos de naturaleza inquieta y celosos de sus privilegios que no tenía intención de suprimirlos» (citado por Albareda Salvadó 2010: 78).

9 Entre estos destacan el príncipe de Darmstadt (tal como lo desarrolla con detalle Albareda Salvadó 2010: 138-142) y la reina Ana de Inglaterra (Albareda Salvadó 2010: 126).

10 El virrey justificaba su falta de eficacia frente a la conspiración arguyendo que había recibido órdenes de actuar con templanza y moderación y «que no solo es dificultoso, pero imposible, se mantenga un reino en que falta la justicia, pues qué podemos esperar de este, en que además de lo que le estrechan sus constituciones, la benignidad del rey no permite la que, sin faltar a ellas y a los privilegios, podía ejecutarse» (Albareda Salvadó 2010: 144)
}

11 Ejemplo de ello es el dictado del Consejo de Estado de 26 de abril de 1706, cuando ya se había producido la revuelta 
Jordi Bermejo Gregorio. Perdón, restitución y teatro musical: Antonio de Zamora y su visión poético-musical de los sublevados españoles durante la Guerra de Sucesión

\section{Antonio de Zamora canta la vuelta a Madrid de Felipe V (1706)}

Entonces, el 25 de julio de 1706 las fuerzas austracistas dirigidas por el portugués marqués de las Minas ocuparon Madrid. La corte hubo de desplazarse en marcha itinerante por varias ciudades hasta llegar a Burgos. En la capital la posición de los grandes se aclaró y muchos se pasaron al bando austracista, ya sea por especulación de intereses propios o por resarcirse de la excesiva represión borbónica de antes de la ocupación (Saavedra Zapater 2000: 479-482). El primero fue el cardenal y secretario del Despacho Universal Luis de Portocarrero, que ofició el Te Deum de proclamación del entronado Carlos III ${ }^{12}$. Le siguieron el conde de Haro, el conde de Oropesa, conde de Tendilla, el de Gálvez, el duque de Nájera, marqués de Mondéjar, el conde de Cardona y el conde de Santa Cruz; «el conde de Lemos, ex coronel de la Guardia Real, junto a su esposa, hermana del duque del Infantado, intentaron unirse a los desertores, pero fueron detenidos por los seguidores leales del rey y enviados como prisioneros a Pamplona» (Kamen 2010: 74), hecho este que tendrá mucha importancia en nuestro tema.

No obstante, en la población había calado el espíritu nacional por la causa del legítimo rey y contra las pretensiones extranjeras ${ }^{13}$. Los madrileños recibieron al nuevo rey con total hostilidad. En el pueblo llano y medio surgió inmediatamente un movimiento de resistencia y lucha contra lo que se entendía como invasor. La lealtad de Madrid hizo que el rey austríaco hubiera de hospedarse extramuros. Entonces, Antonio de Zamora,

cuando dominaron la corte las armas de Portugal, fue uno de los cuatro a quien de orden del general marqués de las Minas llamó el conde de San Pedro, consejero real, para disuadirles la constancia con que en todo aquel barrio mantenían la justa fidelidad, el amor al rey nuestro señor; y despreciando sus repetidos amagos, fue quien respondió por todos con la honra y resolución que a su majestad consta por informes del gobernador del Consejo (citado desde Martín Martínez 2003: 60).

Él, como integrante del pueblo madrileño, juraba lealtad a Felipe V por todo lo que este había significado en relación con los últimos años del siglo XVII. Ciertamente, fue el propio dramaturgo uno de los principales exponentes de la resistencia y voluntad popular respecto a la cuestión de la legitimidad del trono.

en la Corona de Aragón, en el que recuerda a Felipe V que «en los prudentes oídos de V. M. sonará mejor la advertencia de otro rey glorioso y santo como el señor Fernando el Católico, quien cuando, juntos los reinos de Castilla y Aragón, hubo contemplativos que le aconsejaron era buena coyuntura de sujetar más sus súbditos, respondió que poseía sus reinos con las leyes y condiciones que les había jurado, cuyo quebrantamiento hiciera horror incluso a la nación más bárbara» (Albareda Salvadó 2010: 161).

12 Era llamativo que el cardenal Portocarrero, el principal artífice del advenimiento del francés, «decidiera ahora - defenestrado meses atrás por la acción de los ministros franceses- dar "gracias a Dios" por la llegada del primitivo adversario» (Sanz Ayán 1998: XXXVI).

13 Para este tema, véase Guillamón y Muñoz 2003: 513-535. 
Jordi Bermejo Gregorio. Perdón, restitución y teatro musical: Antonio de Zamora y su visión poético-musical de los sublevados españoles durante la Guerra de Sucesión

Antonio de Zamora ensalzó, en cuanto pudo, el ejemplo de Juan Claros Alonso Pérez de Guzmán (1642-1713), XI duque de Medina Sidonia, como heraldo de honor, palabra y valentía durante la ocupación austracista de Madrid. Cantó y propagó con dos sonetos ${ }^{14}$ la actitud del duque de Medina Sidonia al rechazar el chantaje del marqués de las Minas de canjear prisioneros austracistas por la condesa de Niebla -hija del duque- y de sus hijos (Martín Martínez 2003: 60-61), y la relacionó épicamente con el parecido episodio que convirtió en leyenda a su antecesor Alonso Pérez de Guzmán "el Bueno" (1252-1309) ${ }^{15}$. Ya había utilizado Zamora el símil familiar en la comedia heroica El blasón de los Guzmanes y cerco de Tarifa $(1691)^{16}$, cuando el duque fue designado virrey y defensor de Catalunya ante los ataques franceses durante la Guerra de los Nueve Años. En ambos casos la heroicidad y lealtad de Medina Sidonia se postuló como ejemplo de conducta y garante de la soberanía española frente a la agresión foránea: lealtad al rey legítimo. A pesar de la experiencia bélica o violenta de Zamora, su pluma no hizo otra cosa que prolongar la defensa y justa demanda de Felipe V como único destino de España. Con ello, el «lenguaje dinástico consagra su letra y argumento a los derechos propios de unas casas sobre la Corona católica» (Iñurritegui 2002: 245).

Como se desprende de lo dicho, en todo el asunto de lealtad a nivel popular y oficial hay mucho de defensa de la autonomía nacional contra la pretensión extranjera. Pero, paradójicamente, no solamente el nuevo rey español era francés, sino que el propio Antonio de Zamora cantaba la necesidad y el beneficio para España que era la relación con la Francia de Luis XIV. En la introducción-loa de la zarzuela Áspides hay que son basiliscos $(1704)^{17}$, creada como panegírico al nuevo general de los ejércitos franceses en la Península, el mariscal Tessé, se comprende perfectamente que el motivo de la admiración a aquel rey que años antes había sido el enemigo a combatir está en la hegemonía europea que regenta. Entonces, la filiación familiar es el recurso retórico perfecto para componer,

14 Los sonetos son al "Excelentísimo señor", en Zamora 1706: 3; y “A la heroica respuesta con que el excelentísimo señor duque de Medina Sidonia se negó a la proposición del canje de su hija la excelentísima condesa de Niebla e hijos, prisioneras en el ejército del marqués de las Minas, queriendo antes su pérdida que su libertad, con pasaporte de vasallo del duque de Berganza. Soneto de Antonio de Zamora", en Las Poesias de Don Joseph Peres de Montoro y de otros Authores. Recogidas por D. Juan Isidro Faxardo y Monrroy, caballero de la orden de Calatrava y oficial de la Secretaría de Estado, 1712, f. 267v. (BNE: MSS/3916).

15 Desde el castillo de este caballero cristiano, que estaba siendo asediado por los musulmanes, lanzó un cuchillo, cuenta la leyenda, para que mataran con él a su propio hijo antes que sucumbir al chantaje que le hacían los sitiadores infieles. Esa lectura en 1706 daba como resultado una clarísima analogía de preferencia por la libertad de la patria a toda costa.

16 Fue estrenada el 4 de febrero de 1691 en el cuarto de la reina por la compañía de Damián Polope.

17 Fue estrenada el 17 de noviembre de 1704 en casa del duque de Veragua -Pedro Manuel Colón de Portugal, VI duque de Veragua (1651-1710)-, según informa La Gaceta de Madrid del 18 de noviembre de 1704. En ella se dice que «ayer hizo el señor Mariscal de Tessé la función de cubrirse por Grande de España, siendo su padrino el señor duque de Veraguas [sic]; concurrió toda la grandeza de España, y después hubo un gran banquete en casa del señor duque, y a la noche comedia» (Gaceta de Madrid, 53, martes 18 noviembre 1704: 210). 
Jordi Bermejo Gregorio. Perdón, restitución y teatro musical: Antonio de Zamora y su visión poético-musical de los sublevados españoles durante la Guerra de Sucesión

junto con el poder amplificador y relevante de la música, una sencilla a la par que prometedora analogía: si Luis gobierna el personaje alegórico de la Posesión, y vive con «esperanza de que no haya / diminución en sus glorias, / en Filipo hay esperanza / de adquirirlas con la cierta / posesión de las que alcanza» (Martín Martínez 2003: 577, vv. 398-402). Por ello, y como hace trascender el personaje alegórico de la Fortuna y el cuatro de música, «es cada una la sola / y es entrambas» (Martín Martínez 2003: 577, vv. 406-407). Será común en la producción palaciega y circunstancial de Zamora la justificación de la alabanza de Francia por ser Felipe otro sol, providencialmente escogido por la voluntad de Carlos II. En la misma introducción de 1704, cuando Portugal ya se había unido a la Liga de La Haya -la alianza antiborbónica-, se pone el referente del rey francés como inspiración y ayuda con la que «cobrando a Lusitania / vencer espera en Filipo» (Martín Martínez 2003: 577, vv. 348-349).

La reafirmación de la causa felipista después del regreso de Felipe $\mathrm{V}$ a la capital el 4 de octubre fue motivo, por parte de Zamora, de una composición típica para aquellos casos: el largo romance heroico titulado Epinicio métrico, prosphonema numeroso (1706). Con la salida de la corte austracista de Madrid y la vuelta de Felipe V, «ya abrazadas la paz y la justicia / a un oscuro feliz libran el rostro» (Zamora 1706: 5). Esto ha sido posible por «el católico principio / de que nada es sin él, y con él todo» (Zamora 1706: 5). Tal y como se observa en esta larga composición, Madrid y su pueblo celebran la vuelta de la única verdad posible y de la expulsión del «lusitano orgullo, / [que] postrado yace en bélico desdoro» (Zamora 1706: 6). Ciertamente, no deja de ser una composición panegírica y circunstancial que realiza la misma función que la introducción de Áspides hay que son basiliscos, es decir, justificar retórica y poéticamente la legitimidad de Felipe V y la filiación con Luis XIV como garantes de la prosperidad española. En esta sobresale la concepción monárquica de un rey-padre de la patria -idea patriótica en la persona del soberano, como J. M. Iñurritegui declara- en una situación de peligro por el acoso extranjero:

\footnotetext{
Con la dilatada experiencia sedimentada en un pasado de uniones dinásticas e integración de una Monarquía dicha católica, la semántica política de los reinos arroja sobre el tapete la centralidad que en la arquitectura constitucional de la cultura hispana correspondía a una intrincada comprensión de la majestad (Iñurritegui 2002: 246).
}

Pero también nos sirve para comprender la percepción que tenía de los compatriotas sublevados este dramaturgo que cantó la lealtad de los nobles y del pueblo castellano a su rey. Y, como se verá, es muy diferente de su opinión hacia los portugueses.

En dos cuartetas endecasílabas está condensado el mensaje y, a la vez, la concepción que Zamora tenía de los aragoneses después de la significativa y emblemática victoria del pueblo castellano sobre la imposición austracista foránea: 


\title{
Jordi Bermejo Gregorio. Perdón, restitución y teatro musical: Antonio de Zamora y su visión poético-musical de los sublevados españoles durante la Guerra de Sucesión
}

\author{
Si en las murallas ásperas de Cauca \\ busca abrigo el temor, bien que remoto, \\ azogar sabrá el Júcar a su estrago \\ para trágico espejo un cristal roto. \\ Transcienda, pues, a la Colonia Julia, \\ que allá en sus rebelados sediciosos, \\ con el amago solo de un castigo \\ se logrará el blasón de dos destrozos. (Zamora 1706: 6-7)
}

El mensaje de Zamora está dirigida al reino de Valencia y, especialmente, al Principado de Catalunya -reconociéndose Barcelona con las primeras palabras de su nombre romano completo $^{18}$-, y es claro y directo: que tomen advertencia del caso de la expulsión de los austracistas de Madrid por el pueblo y la justicia; que reconsideren la situación y que sepan que su rendición y arrepentimiento devolverá la paz y el orden a los españoles, entre los que están ellos como compatriotas. Es una recomendación y deseo de la vuelta a la cordura y a la lealtad hacia el legítimo rey para que no haya más sacrificios ni víctimas españolas, pues las portuguesas ya han sido suficientes y han sido ejemplo de castigo al bando sublevado. En el presente histórico de ese momento, ese mensaje de perdón paternal y reintegración de los hijos descarriados se enriquecía con la amnistía que el rey Felipe firmó el 5 de agosto de 1706 en toda Castilla ${ }^{19}$. De ahí la metáfora con el agua de la figura alegórica del Júcar -que llevará, como un espejo, el reflejo de lo acontecido con los portugueses en Madrid a los valencianos- y de ahí la referencia a ese «blasón de dos destrozos»: la rendición de Valencia y Catalunya conseguirá el blasón que es la paz.

\section{La zarzuela Viento es la dicha de amor (1708): perdón y restitución de los condes de Lemos.}

Con este homenaje y canto a la victoria de Madrid sobre sus opositores pide Zamora el cese de las hostilidades y la vuelta a la cohesión patria, que pasa por el reconocimiento de Felipe $\mathrm{V}$ como legítimo soberano de España; que se desengañen de los embustes de los extranjeros y que pidan un perdón que se les concederá. Si bien este testimonio poético nos transmite una idea bien intencionada desde uno de los bandos de la guerra, no será el único que el dramaturgo madrileño cree. Dos zarzuelas de 1708 estarán creadas alrededor de ese mensaje de expiación del error de sublevación mediante el arrepentimiento y el consecuente perdón: Desprecios vengan desprecios ${ }^{20}$ y

18 El nombre completo de la ciudad fundada entre el 15-10 a. C. fue Colonia Iulia Augusta Faventia Paterna Barcino.

19 Decreto que firmado del rey Felipe V e impreso de su orden real se publicó en la Corte de Madrid el día 5 de agosto del año 1706 en que da perdón general a todas las personas que bubiesen concurrido en la proclamación de Rey de España en la persona del Señor Carlos de Austria, su archiduque, y que se bubiesen declarado por sus parciales (BNE: MSS/2569/18). No obstante, Juan C. Saavedra Zapater (2000), como más adelante se expondrá, demostró que esta amnistía ideal no se llevó a cabo en esos términos.

20 El título completo es Zarzuela música en la celebridad de años de la excelentísima Condesa de Lemos intitulada Desprecios vengan desprecios (Zamora 1741: 1r). La zarzuela ocupa los folios 1r-36r de dicho manuscrito.

SCRIPTA, Revista internacional de literatura i cultura medieval i moderna, núm. 11/juny 2018/pp. 237-257

ISSN: 2340 - 4841 doi:10.7203/SCRIPTA.11.12594 
Jordi Bermejo Gregorio. Perdón, restitución y teatro musical: Antonio de Zamora y su visión poético-musical de los sublevados españoles durante la Guerra de Sucesión

Viento es la dicha de amor ${ }^{21}$. Varios investigadores las han situado entre 1706 y 1708 (Martín Martínez 2003: 59 y González Roncero 2011: 143), pero la interpretación de la significación de estas dos zarzuelas inéditas evidencia que son de 1708. Lo más significativo es que Zamora -aquel que había defendido ante el marqués de las Minas a Felipe $V$ como único rey posible- las escribe para los respectivos aniversarios del conde y la condesa de $\operatorname{Lemos}^{22}$, aquellos mismos que habían sido encarcelados en Pamplona por querer pasarse al bando austracista en la entrada de Carlos III en Madrid (Kamen 2010: 74) ${ }^{23}$. Además de conocerse autor y condes por haber estado relacionado el primero con las fiestas y entretenimientos literarios que la condesa organizaba ${ }^{24}$, los posibles motivos de la creación de esta última zarzuela son, cuanto menos, lógicas, coherentes y posibles (González Roncero 2011: 143): los condes estuvieron recluidos en el castillo de Pamplona del 25 de agosto de 1706 (Saavedra Zapater 2000: 479) hasta el 29 de agosto de 1707, cuando, con motivo del nacimiento del príncipe Luis, se emitió un perdón general de presos (Linde Paniagua 1977: 11)25. Según González Roncero, «su primer cumpleaños tras la liberación sería motivo de celebración» (2011: 143). En la disyuntiva de la fecha de creación de la zarzuela la "ocasionalidad"26 de Viento es

21 El título completo es Viento es la dicha de amor, zarzuela música que representó el día de los años del señor conde de Lemos (Zamora 1741: 37r). La zarzuela ocupa los folios 37r-36r de dicho manuscrito.

22 El XI conde de Lemos fue Ginés Miguel María de la Concepción Ruiz de Castro Andrade y Portugal Osorio (1666-1741), cuyo día de nacimiento es el 16 de octubre (Álvarez y Baena 1790: 344). José Antonio Álvarez y Baena destacó el aspecto positivo de su carrera militar y cortesana: «Luego que tuvo edad empezó a servir en la Marina, hasta el grado de Capitán General de las Galeras de Nápoles, empleo que ejercía año de 1701. Fue también Gentil-Hombre de Cámara del Señor Don Felipe V» (Álvarez y Baena 1790: 345). Su esposa, la condesa consorte de Lemos, fue Catalina Lorenza de Mendoza y Silva Haro y Aragón (1669-1727), hija del IV duque de Pastrana y de la VIII duquesa del Infantado. Para saber más sobre este matrimonio y su relación con la música con finalidad política y de autopromoción, véase Pelliccia 2016: 332.

23 El conde de Lemos, si bien partidario de Felipe V al inicio de la contienda (Albareda Salvadó 2010: 103), ya había mostrado su malestar cuando renunció a los cargos palaciegos ante la desidia con la que los nuevos ministros franceses del rey trataban -mejor dicho, minusvaloraban- la industria y las manufacturas españolas (Saavedra Zapater 2000: 471).

24 Zamora había estrenado, con música del abate Francesco de Russi, la opereta Fábula de Polifemo y Galatea días antes del 21 de enero de 1698 «para diversión y festejo de la excelent[ísima] señora doña Catalina de Silva y Mendoza, condesa de Lemos y Andrade» (BNE: T/546, portada). Muy posiblemente al madrileño se le confió esta fiesta, a la que acudieron los reyes, debido al gran éxito y al agrado por parte del público -en el que seguro estaban los condes de Lemos- de las representaciones de Muerte en amor es ausencia, un año antes. Incluso, en febrero de 1706 -antes de la ocupación de la capital por los austracistas- Zamora participó con un soneto en el libro de Fernando Triviño y Figueroa Compás fiel del ánimo. Definición, división y práctica de la modestia, considerada como virtud moral y evangélica, que estaba dedicado a la condesa de Lemos (Martín Martínez 2003: 59).

25 En efecto, hubo un perdón general para los presos por el nacimiento del príncipe de Asturias (25 de agosto de 1707) con el objetivo de que se arrepintieran y enmendasen sus posiciones anteriores (Saavedra Zapater 2000: 495).

26 El espectáculo palaciego o fiesta real barroca es una ceremonia espectacular elitista, ostentosa, dinámica y aglutinadora de todas las artes (unión artística de poesía, música y escenografía mediante el nexo de la actuación/ teatralidad de lo que resulta una supradimensión artística) motivada por una precisa y determinada "ocasionalidad" espacio-temporal e histórico-política. Según Hans-Georg Gadamer, «ocasionalidad quiere decir que el significado de 


\section{Jordi Bermejo Gregorio. Perdón, restitución y teatro musical: Antonio de Zamora y su visión poético-musical de los sublevados españoles durante la Guerra de Sucesión}

la dicha de amor mucho puede aportar sobre la reprobación de los condes de Lemos y la restitución de su lealtad a Felipe V.

Antonio de Zamora constituye principalmente la zarzuela mediante el episodio de la náyade Liríope -representante del elemento del agua- y las pretensiones que tiene sobre ella Céfiro, dios del homónimo viento. Es muy significativo el hecho de que en la tradición clásica el amado de Liríope sea el dios-río Cefiso, con el que tendrá al malogrado Narciso ${ }^{27}$. Pero a Antonio de Zamora este episodio no le servía para la utilidad simbólica y "ocasional" que pretendía, así que, ante el parecido fonético entre los dos personajes masculinos, escogió al elemento del viento, Céfiro, que reforzaba el contraste con el agua. Céfiro se presenta de la manera más representativa que ha de tener durante todo el desarrollo de la pieza: incendia el templo de Amor por el despecho producido por el rechazo de una de sus sacerdotisas, Liríope. Tiresias, astrológico adivino, predice el nacimiento de Narciso, hijo de Liríope y Céfiro, que morirá desgraciado cuando se conozca a él mismo. Tras ello la náyade y sacerdotisa se desespera y se intenta suicidar para evitar así la fatalidad del hado. Pero los personajes secundarios van en su busca y logran detenerla. Esto permite que Céfiro reemprenda su obstinado deseo y vuelva dispuesto a llevársela a toda costa. Liríope, en una impresionante puesta en escena musical y escenográfica, donde canta y hace volar las flores del ramo de la ninfa, está a punto de ser definitivamente seducida por el que la quiere privar de su libertad y consumar su trágico hado. Lo intenta impedir pidiéndoles a las otras ninfas ayuda, pero Céfiro vuelve a disipar la voz de la joven mediante su canto, mediante el viento. De esa manera Céfiro consigue su objetivo y se lleva a Liríope a su elemento, el aire. Seguidamente, Amor se presenta enfurecido por no haber podido evitar que aquel que había quemado su templo y raptado a su sacerdotisa se saliera con la suya:

Mientras esta música y versos, que serán a un mismo tiempo, elevándose en tramoya rápida, ocultándose Céfiro y Lirípe, se prosigue la tempestad, y sale Amor.

\begin{tabular}{|c|c|}
\hline UnOS & Divina Venus, ¿qué es esto? \\
\hline \multirow[t]{2}{*}{ Otros } & ¿Qué es esto, sagrado Amor? \\
\hline & Recitado \\
\hline Canta AMOR & $\begin{array}{l}\text { Es una injusta violencia, } \\
\text { y una atrevida pasión, } \\
\text { que en el aire disfraza el fuego }\end{array}$ \\
\hline
\end{tabular}

su contenido se determina desde la ocasión a la que se refiere, de manera que este significado contiene entonces más de lo que contendría si no hubiese tal ocasión» (Gadamer 1977: 194). Aplicado al ámbito y a la dimensión palaciega, la "ocasionalidad" está configurada mediante el mensaje oficial y panegírico-propagandístico, y la intencionalidad extraoficial del autor según su interpretación de las circunstancias políticas próximas a esa ocasión por la que se hace la pieza, enlazándose con la función del espectáculo en sí como reflejo de la persona homenajeada y de lo que esta representa.

27 En las Metamorfosis de Ovidio esto se cuenta en el tercer libro, vv. 341-352. 


\title{
Jordi Bermejo Gregorio. Perdón, restitución y teatro musical: Antonio de Zamora y su visión poético-musical de los sublevados españoles durante la Guerra de Sucesión
}

\author{
pues el aire disfrazó \\ a Céfiro, bien como hijo \\ de su vaga indignación, \\ en sí mismo desmentido. \\ En este jardín robó \\ a Liríope, que ya \\ huéspeda de otra mansión \\ quejas alterna, por más \\ que el amante robador \\ su voz confunde, diciendo \\ la prevenida canción (Zamora 1744: 93).
}

No parece casualidad que este número espectacular tenga como protagonista al dios Amor iracundo por la afrenta sufrida - y esté construido mediante la suntuosidad y boato del canto, de la música y de las tramoyas. No es arbitrario que sea Amor el dios que rige el destino del resto de personajes en esta zarzuela, como tampoco lo había sido en algunas de las anteriores de Zamora. En la ópera Quinto elemento es amor (1701) - primera pieza teatral que viera el nuevo monarca- el madrileño había presentado a una Venus dubitativa sobre la buena o mala naturaleza de su hijo ${ }^{28}$. Para resolver sus dudas, es el mismo Amor el que recrea cuatro parejas de amantes mitológicos - cada una representante de un elemento del cosmos- para enseñarle que el devenir de todas ellas tiene a un quinto elemento como regente que, al fin y al cabo, es su razón de ser. Este no es otro que el amor, fuerza poderosa que tiene el imperio de todos los elementos y por el cual debe su contrapuesto equilibrio el universo. Si bueno o malo, es indiferente: lo importante es que es el amor la única fuerza que gobierna la naturaleza y a los humanos - a los dioses inclusive-, por lo que siempre estarán legitimados su poder y su autoridad.

En 1707 Antonio de Zamora ya había hecho algo parecido con Todo lo vence el amor, creada para celebrar el nacimiento del primer hijo de Felipe V y María Luisa de Saboya, el príncipe Luis, que propiciaría la amnistía general a presos austracistas en Castilla de la que se beneficiarán los condes de Lemos. La historia mitológica escogida en esta ocasión -las adversidades y las hazañas de Belerofonte para conseguir la mano de su amada Filónoe- otorga de por sí una significación "ocasional" elocuente debidamente contextualizada. También enmarcada en el contexto político de la Guerra de Sucesión, Todo lo vence el amor ahonda en los impedimentos que el cielo -los dioses Júpiter y Marte- ponen al héroe para que los mortales lo acepten como esposo de Filónoe. La fuerza contradictoria y constantemente beligerante del universo influye de tal manera en los elementos que

28 Inscrita dentro de los festejos que la corte hacía a la entrada del monarca en la capital el 14 de abril del mismo año, la continuación de la representatividad de la monarquía anterior hizo que en el texto -único testimonio que se tiene de la fiesta- se constituyera poético-musicalmente con las formas tradicionales castellanas anteriores, si bien no se deja de experimentar con largas estrofas de hexasílabos y dodecasílabos. Para un mayor conocimiento de este aspecto, véase Bermejo Gregorio 2017: 91-105. 


\title{
Jordi Bermejo Gregorio. Perdón, restitución y teatro musical: Antonio de Zamora y su visión poético-musical de los sublevados españoles durante la Guerra de Sucesión
}

ningún mortal con acciones mortales puede tergiversar o torcer su poder, por lo que, al enterarse Amor del agravio que a su autoridad se está haciendo al impedir que los amantes se amen, aparece como deus ex machina al final de la pieza para resolver positivamente la trama. Y lo hace igual que en Viento es la dicha de amor. cantando una aria castellana:

Área

\author{
Aunque de Júpiter la sacra cólera \\ máximas busque, que asusten tu fe, \\ yo triunfaré, sí, sí, yo triunfaré, \\ pues sus escándalos no pueden rígidos \\ émulos ser de mi sacro laurel; \\ yo triunfaré, sí, sí, yo triunfaré (Zamora 1722: 40).
}

Lo decisivo de estas apariciones en este preciso formato poético-musical imprime al propio Amor, a su legitimidad y a la justicia un tono épico y dramático excelente para, precisamente, enfatizar el poder absoluto de ese quinto elemento; aquel que puede favorecer la suerte de los mortales si estos demuestran su valía, sinceridad y capacidad de sacrificio. Eso es Amor en la dimensión ficticia de la fábula: la única conexión que pueden suprimir y poseer los mortales con la divinidad de lo imperecedero, con lo victorioso y lo invencible de las causas nobles. Y, aplicándolo ahora al presente histórico de dichas fiestas reales -a la ocasión de creación y, por lo tanto, de interpretación-, Felipe es ese quinto elemento que gobierne a los otros cuatro y a todo el Olimpo. Por ese motivo -y continuando con el concepto presentado en Viento es la dicha de amor-Zamora hace que sea un dios del viento, Céfiro, el amante de la náyade Liríope, y no el dios fluvial Cefiso, como la mitología estipula. Por lo tanto, estamos ante el mismo tratamiento simbólico. No en vano José M. Iñurritegui ya estudió el alto componente paternal y de amor en la proyección que de Felipe $\mathrm{V}$ hacían muchos textos teóricos de política -incluso en los Decretos de Nueva Planta de Aragón y Valencia- ${ }^{29}$. La autoridad del soberano es la significación que se esconde como relación alusiva de semejanza tras el emblema dinámico que es el dios Amor: como aquel amor, solo la Monarquía del legítimo y justo rey es la fuerza ordenadora, cohesionadora y armonizadora de todo el cosmos español.

Entonces, y dado el altísimo grado de representatividad áulica y auto-expresión que emana de estas apariciones del dios, solamente mediante los números más espectaculares de música y escenografía de la fiesta se podía resolver el entuerto que contra "Amor" se había ocasionado en cada pieza. Como se advierte, Zamora sigue explotando el recurso del lenguaje de los dioses de Calderón e Hidalgo como «parte esencial de la estructura dramática» (Flórez Asensio 2006: 235), aunque en

29 «El entendimiento paternal y pastoral del poder político que aflora con naturalidad en el cuadro de un ordo amoris, del orden que genera el amor y tiende un puente entre el saeculum y la patria paradisii, remite a un género de libertad, la individual que predica y requiere la religión, despojada de la sustancia territorial de aquellas otras libertades que, identificadas con la patria, permiten figurar al derecho como un orden que contenido dentro de la propia república gobierna en última instancia la comunidad política» (Iñurritegui 2002: 250). 


\section{Jordi Bermejo Gregorio. Perdón, restitución y teatro musical: Antonio de Zamora y su visión poético-musical de los sublevados españoles durante la Guerra de Sucesión}

este caso adaptado a la modernidad operística que imperaba en la época. La esencia trágica de los protagonistas - mortales y vasallos del amor, quisieran o no- debía ser contrarrestada por la claridad del cielo, del orbe celestial y de las autoridades que lo regentan, para así poder concluir de manera armónica y absoluta la trama. De la música, de la voz sobrehumana y atemporal, vienen las respuestas de las preguntas que el ser humano no sabe ni puede contestar ${ }^{30}$. Por ello, en estas fiestas de Zamora tan estrechamente vinculadas a Felipe V -y de ellas tan necesitadas la imagen y la propaganda de este- siempre Amor ha de triunfar y todo vencer, no por recurso lírico o sentimental, sino por la exigencia del símbolo cosmológico que es la legítima y justa autoridad de Felipe V. Y, para conseguir precisamente esto, no había a principios del siglo XVIII otro recurso mejor que la dimensión multiartística de números escénicos poético-musicales, tal y como los ideó Calderón.

Así pues, el desenlace de Viento es la dicha de amor conlleva la lógica resolución de la acción y la restitución del orden de la fábula gracias a al poder de Amor. El hado de Céfiro y Liríope se cumple, a pesar de que él hubiera enojado al dios y ella intentado evitar su destino. Cómo no, esto se materializa en escena con un dúo musical de tramoya y espectáculo:

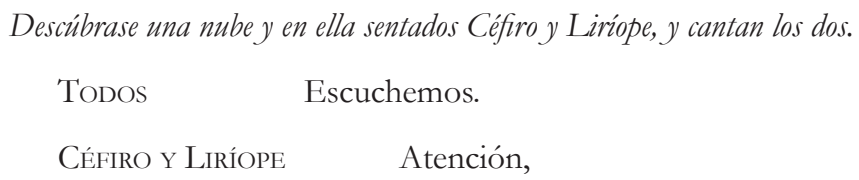

30 Nótese cómo se cumple esta idea de solución de la duda humana por la voz musical divina en este pasaje de, precisamente, Las fortunas de Andrómeda y Perseo (1653). Calderón hace hablar a Perseo a propósito de la naturaleza de la voz que de arriba escucha:

\begin{tabular}{|c|c|}
\hline Perseo & $\begin{array}{l}\text { Pues que ya en süaves ecos } \\
\text { oigo las voces que suelen } \\
\text { tener el aire suspenso } \\
\text { cuando alguna deidad pisa } \\
\text { la tierra (porque su acento } \\
\text { métricamente sonoro } \\
\text { suena más dulce que el nuestro) } \\
\text { con él de hablar. Oh, tú, } \\
\text { deidad que escucho y no veo, } \\
\text { si eres mi oráculo, dime } \\
\text { ¿quién soy? }\end{array}$ \\
\hline MúsICA (dentro) & Tú lo sabrás presto. \\
\hline Perseo & ¿Quién me lo ha de decir? \\
\hline MúsICA & Nadie. \\
\hline Perseo & $\begin{array}{l}\text { Pues ¿cómo puede ser eso } \\
\text { decirlo y nadie? }\end{array}$ \\
\hline Música & Llegando... \\
\hline PERSEO & Prosigue, que no te entiendo. \\
\hline Música & A decirlo, sin decirlo \\
\hline & y a saberlo, sin saberlo. (Valbuena Briones 1969: 1645-1646) \\
\hline
\end{tabular}




\section{Jordi Bermejo Gregorio. Perdón, restitución y teatro musical: Antonio de Zamora y su visión poético-musical de los sublevados españoles durante la Guerra de Sucesión}

\begin{tabular}{|c|c|}
\hline & $\begin{array}{l}\text { que ya de Amor es lisonja } \\
\text { lo que fue ofensa de amor. } \\
\text { Atención, atención. }\end{array}$ \\
\hline CÉFIro & $\begin{array}{l}\text { Cupido, si mi despecho } \\
\text { tu mejor templo abrasó, } \\
\text { hoy por Liríope tienes } \\
\text { el templo en mi corazón. }\end{array}$ \\
\hline LiRíope & $\begin{array}{l}\text { Ninfas, que en el vago imperio } \\
\text { que Céfiro me ofreció, } \\
\text { el que fue hasta hoy agravio } \\
\text { desde hoy es adulación. (Zamora 1744: 94) }\end{array}$ \\
\hline
\end{tabular}

Con este giro, el dios se siente satisfecho y el equilibrio cosmológico se ha restablecido; nunca fuerza o elemento alguno podrá doblegar el poder del cielo, ni siquiera el hijo del viento, pues este cae rendido al único poder del universo ${ }^{31}$.

Tras lo dicho, la significación política de esta zarzuela se origina con la relación alusiva de semejanza de la "ocasionalidad". Resulta claro el mensaje de cumplimiento y aceptación de la ley y de la justicia - es decir, el amor- que debe regentar la vida de los hombres de bien, siendo el conde de Lemos un gran exponente de ello. Las probabilidades de que esta fiesta fuera realizada para después del presidio del conde tras el acto de deslealtad hacia Felipe V se acrecientan con el mensaje "ocasional" que Zamora, utilizando la fábula modificada de Liríope y Céfiro, transmite al homenajeado. No es casualidad que el dramaturgo difunda exactamente el mismo mensaje que la amnistía aplicada a los reinos de Aragón y Valencia en $1707^{32}$, y que ha sido comentado por J. M. Iñurritegui:

Los propios términos en los que la introspección era convocada, con tan recurrente llamada de atención sobre la caracterización amorosa del poder político, ubicaban por tanto con más propiedad a unos derechos y acomodaban su vigencia entre las derivaciones políticas provocadas por el singular y obligado ejercicio de la magnificencia -y regia largatio- por parte del soberano (Iñurritegui 2002: 287)

31 Precisamente con este mensaje acaba Viento es la dicha de amor, zarzuela dedicada al conde de Lemos:

CÉFIro Con que aplaudiendo mi dicha

en tanto que vuelta doy

al boreal Alcázar mío,

repita la aclamación.

Todos y músICA Que vano intenta el rigor

frustrar de amor el intento,

pues para adular al viento,

viento es la dicha de amor (Zamora 1744: 94).

32 Como es lógico, la voluntad de amnistía y perdón a todos los vasallos del crimen de rebelión y felonía tenía por condición que «sin omisión ni tardanza alguna, se nos reconozca por su legítimo rey y señor natural» (citado por Iñurritegui 2002: 287). Además, Felipe V «perdonó por el Auto de 7-3-1707 a los soldados desertores que se reintegraran en sus respectivos cuerpos» (Linde Paniagua 1977: 9). 
Por lo tanto, y después de la demostración de magnanimidad y piedad del justo y legítimo rey con su amnistía, lo que ha de hacer el conde es rectificar su afrenta y someterse a la autoridad del rey, pues no ha de tener miedo del irremediable destino que le espera a España. A pesar de las dudas y del temor que pudieran surgir en el panorama de la guerra, los condes de Lemos han de tener plena confianza en la única opción que permitirá el equilibrio y la paz de los reinos y han de vencer sus miedos -que son equivocaciones- al hado, que está escrito por Amor, es decir, Felipe V. Así pues, deben pedir públicamente disculpas, jurarle la misma fidelidad que Liríope y Céfiro a Amor y colaborar en todo lo que pueda con el buen desarrollo de la Guerra de Sucesión a favor de aquel que, como el dios a Céfiro, les ha perdonado. La experiencia en la cárcel les ha tenido que servido de mucho - «aplaudiendo mi dicha» (Zamora 1744: 94)-: corregir la actitud hacia el soberano que les ha permitido regresar a casa - «en tanto que vuelta doy / al boreal Alcázar mío» (Zamora 1744: 94). A él le deben la libertad, entendiéndose que el olvido -y, por lo tanto, su perdón- es la dicha del poder, es decir, de la gracia divina y beneficiaria que hay en el rey ${ }^{33}$. Como los condes de Lemos, la decisión del Felipe $\mathrm{V}$ de otorgar el perdón a los nobles que lo habían traicionado barrió de inmediato la oposición interna que había tenido desde su llegada a España y lo aupó como señor modélico. El caso más representativo de esto fue el del cardenal de Portocarrero ${ }^{34}$.

No cabe duda de la implicación política de esta zarzuela contextualizada históricamente, y de lo fundamental que resultan esos números escénicos para la creación de una emblemática y áulica dimensión poético-musical. Pues bien, la fiesta real para el aniversario de la condesa -Desprecios vengan desprecios- es todavía más relevante. En esta ocasión Zamora parte del mito de Níobe, pero hace que esta y Febo (Apolo) se enamoren, en contra de la voluntad de Diana y Latona, la madre de los dioses hermanos. Nos encontramos ante una reelaboración propiciada por la necesidad de adaptar el episodio mitológico para que se cumpla y pueda observarse la relación alusiva de semejanza entre fábula de la pieza y el presente histórico de la ocasión del estreno. Y, como siempre ocurre, en el final de la zarzuela se encuentra el momento en que la referencia entre la expresión mitológica y la realidad que motivó la creación de la fiesta es más estrecha y deja entrever mejor el significado “ocasional”. En él se encuentran estos versos:

33 Juan C. Saavedra Zapater resume de esta manera qué significaba ser perdonado: «Con todo, y como sucediera con el clero, el requisito prioritario para ser perdonados consiste en demostrar con hechos fehacientes el arrepentimiento por sus pasadas acciones y su voluntad de someterse a la soberanía del rey; un acto que es, sin lugar a duda, una expresión de vasallaje a partir del cual el monarca puede conceder o desestimar el perdón como responsable máximo de la justicia» (Saavedra Zapater 2000: 494).

34 Después de la amnistía, el cardenal «consiguió mantenerse en su arzobispado de Toledo, pidiendo perdón a Felipe $\mathrm{V}$ y ofreciéndole de nuevo su lealtad. Esta no fue rechazada pero desde luego sí puesta en entredicho. Portocarrero no volvió a ejercer nunca un cargo político, aunque en su dignidad de titular de la sede primada de Toledo, bautizó al príncipe de Asturias, don Luis, en diciembre de 1707 y un año más tarde actuó de padrino en el juramento que el príncipe hizo en la iglesia de San Jerónimo como heredero de la Corona. Fue su último acto público relevante antes de fallecer» (Sanz Ayán 1998: XXXVIII). 


\title{
Jordi Bermejo Gregorio. Perdón, restitución y teatro musical: Antonio de Zamora y su visión poético-musical de los sublevados españoles durante la Guerra de Sucesión
}

\author{
CANTAN TODOS En eternidad florida \\ viva su hermoso arrebol \\ y al feliz consorte unida \\ asegure el sol la vida \\ del mejor rayo del sol. (Zamora 1741: 36r)
}

La condesa, encerrada también junto a su marido en la prisión navarra, salió con él. Se les culpaba exactamente de los mismos cargos. Una vez liberados, y teniendo en cuenta la significación de la zarzuela anterior, todo se presenta evidente y claro. Una vez que han aprendido la lección de la sublevación y traición al rey, ella, «al feliz consorte unida», ha de procurarse un buen porvenir, y este solamente será posible si sigue la senda de la justicia y de lo correcto, es decir, «del mejor rayo del sol». Sobran los comentarios entre la analogía simbólica entre Felipe V y su relación con su ilustre abuelo Luis XIV. La simbología de las fiestas reales en tiempos del rey Planeta -Felipe IV- se ha actualizado y adaptado al nuevo panorama geopolítico de la España de principios del siglo XVIII.

Así pues, y tras todo lo dicho, toma cuerpo la posibilidad de que solamente pudieron ser ejecutadas ambas zarzuelas después de la puesta en libertad de los condes y de la consiguiente disculpa pública, que tuvo que realizarse sobre el último tercio del año 1707. Aunque el aniversario del conde fuera el 16 de octubre -es decir, que en 1707 el conde cumplió años lejos de la prisión-, la proximidad con el edicto de amnistía (29 de agosto de 1707) -y la consiguiente aplicación y traslado de los exreos a la capital, a sus posesiones- hace realmente difícil por falta de tiempo que puediera organizarse una zarzuela real como Viento es la dicha de amor para ese año. Incluso hay que valorar que los condes tuvieran otras prioridades, como por ejemplo la recuperación de la normalidad. Es por ello que, ante la significación "ocasional" comentada, esta zarzuela fue problablemente estrenada el 16 de octubre de 1708. El hecho de que no se haya encontrado la fecha del cumpleaños de la condesa imposibilita la datación exacta de Desprecios vengan desprecios - ya que tanto puede haber sido antes como después del de su marido-, pero, por las mismas razones que con la anterior zarzuela, es poco probable que se hiciera en el último tercio de 1707, sino durante 1708.

\section{Conclusiones}

Los mensajes de estas dos zarzuelas se yerguen, contextualizados por las situaciones históricas y por la pluma que las escribió, en enorme similitud al del Epinicio métrico de 1706. Como en el largo romance heroico, la concepción de los sublevados es la de compatriotas españoles que han cometido el error de dejarse engañar por los embustes y embelecos de los extranjeros de la coalición antiborbónica. Estos, como envidiosos de la figura de Felipe V, quieren conseguir por la fuerza lo que no pueden por verdad, por ley -en este caso por testamento de Carlos II- ni por justicia divina. Por eso los condes de Lemos no dudaron en prometer la solución a las afrentas que habían ocasionado por la confusión y la equivocación. Estas eran de la misma naturaleza que las que hizo que tanto el reino de Valencia como el Principado -cuya capital es la moderna «Colonia 
Julia»- renegaran de Felipe V. Pero, como las zarzuelas -especialmente Viento es la dicha de amorhan mostrado, una vez reconocido el error -que pudiera provenir de la observación del espejo que lleva el Júcar o por la experimentación del poder omnímodo e incuestionable del Amor-, en el arrepentimiento está la renuncia y la redención de esos yerros pasados. Así pues, la magnanimidad y preocupación por sus súbditos de aquel quinto elemento restituirá la paz y la armonía, y permitirá el glorioso porvenir que su nombre, su linaje y su figura ha de traer a España. Para este resurgir de la confraternidad entre los españoles, antes enfrentados, era fundamental la amnistía y el perdón general, sin rencores, de los súbditos sublevados, tal y como sucedió con los condes de Lemos. Como se ha ido viendo durante todo el estudio, para este discurso en Zamora es fundamental la comparación de trato entre los enemigos extranjeros -ya fueran franceses o portugueses- y los sublevados compatriotas.

Pero, a diferencia del romance heroico de 1706, en las zarzuelas de 1708 Antonio de Zamora lo consigue mediante una ostentación de la poesía, de la música y de la tramoya que sobrepasa en mucho el resultado o efecto que solo unos versos claramente panegíricos pueden hacer. Mediante la explotación de las dimensiones intelectual y sensorial -catalizadas por lo teatral-, la realidad y concepción de Felipe $\mathrm{V}$ y su gobierno que el dramaturgo quiere transmitir son elevadas cosmológicamente hasta la verdad absoluta y expresión simbólica de Dios y de su voluntad ${ }^{35}$. Entonces, la simbología y la utilización de la música y el canto fundidos en espectaculares números escénicos adquieren un inigualable pragmatismo político para los homenajeados y receptores de las zarzuelas: los condes arrepentidos cuyo vasallaje al rey ha vuelto. Nunca con intención de humillación ni de someter mediante la victoria, en el mensaje y concepción de la restitución de la paz en Zamora, después del arrepentimiento e innegable perdón, no hay discurso alguno de vencidos ni vencedores. De un modo exquisitamente pedagógico, el dramaturgo utilizó todos los recursos del espectáculo regio que eran comunes en el teatro palaciego con Carlos II para emitir un mensaje de prosperidad basada en la cohesión y coherencia leales a Felipe V, legítimo rey de España por la gracia de Dios. En definitiva, y especialmente con Viento es la dicha de amor, se ha demostrado la importancia y la potencia propagandística y retórica que adquiere el mensaje de arrepentimiento y fin de las hostilidades fratricidas en las formas poético-musicales y escénicamente espectaculares de las fiestas reales, en una ocasión y unas circunstancias política y socialmente tan delicadas como fue la Guerra de Sucesión en España.

Esto es lo que Zamora intentó transmitir. Por el tono compasivo, amistoso y fraternal del madrileño, convencido del respeto que el rey tendría en relación con las leyes, parece ser que para el dramaturgo debiera haber sido así. Desde una visión castellana conciliadora, el tratamiento del compatriota

35 Joaquim Albareda recuerda que «en la argumentación pro borbónica el carácter providencialista de la monarquía jugó un rol decisivo, tal como lo demuestra el siguiente párrafo de un impreso: "nuestro rey y sr. Felipe $\mathrm{V}$ reina por disposición divina, tan poderosa contra las ideas humanas. No es rey por el consejo de los hombres; por la voluntad divina vino de Francia a ser rey. ¿Quién, pues, puede negarle la obediencia? ¿Quién contrasta la voluntad divina?”» (Albareda Salvadó 2010: 107-108). 


\section{Jordi Bermejo Gregorio. Perdón, restitución y teatro musical: Antonio de Zamora y su visión poético-musical de los sublevados españoles durante la Guerra de Sucesión}

rebelde por Antonio de Zamora está muy próximo al perdón por la ruina de una contienda civil y evidencia un halo de esperanza en los españoles, propiciada esta por la ilusión de la llegada de la dinastía que estaba gobernando Europa. Quizás esto obnubiló su percepción de la realidad inmediatamente posterior a la recuperación de Madrid por los borbónicos ${ }^{36}$ e imposibilitó que previera la represión y supresión de las libertades forales de los reinos de la Corona de Aragón que Felipe $\mathrm{V}^{37}$ y sus ministros tenían diseñadas desde hacía tiempo ${ }^{38}$. Por desgracia, la piedad y perdón de Zamora pecaban de inocentes ante unos hermanos culpables por engaño, que el gobierno y la justicia de Felipe V trató desde el primer momento de manera despótica, despectiva e ilícitamente represiva $^{39}$. O quizás, dentro de todo, lo que creó Zamora no fue más que la construcción de una interesada imagen de deseo que ocultara el crudo y sin sentido ser.

36 «El hecho mismo de que se publicara una memoria de las personas que acompañaron el estandarte con motivo de la proclamación del archiduque en Madrid es un magnífico ejemplo de que Felipe $\mathrm{V}$ y sus asesores no estaban por la labor de olvidar la desafección de los castellanos» (Saavedra Zapater 2000: 479).

37 En las negociaciones de paz de Utrecht, a pesar de que los ingleses pidieron que, una vez rendidos y vueltos los catalanes a la lealtad de Felipe V, se mantuvieran los privilegios forales tradicionales, el embajador conde de Monteleón respondió que el deseo del rey era limitarse a la concesión de la amnistía, «porque en lo tocante a los privilegios que los reyes, por pura bondad, otorgaron a los catalanes, se han hecho indignos de ellos por su mala conducta» (citado desde Albareda Salvadó 2010: 389). De esta forma justificaba a su abuelo Luis XIV -que también era proclive a restituir la situación de la Corona de Aragón antes de la guerra- el motivo por el que no podía devolver la realidad compuesta a la monarquía que había heredado: «no es por odio ni por sentimiento de venganza por lo que siempre me he negado a esta restitución, sino porque significaría anular mi autoridad y exponerme a revueltas continuas, hacer revivir lo que su rebelión ha extinguido y que tantas veces experimentaron los reyes, mis predecesores, que quedaron debilitados a causa de semejantes rebeliones que habían usurpado su autoridad. [...] Si [Carlos VI] se ha comprometido en favor de los catalanes y los mallorquines, ha hecho mal y, en todo caso, debe conformarse del mismo modo que lo ha hecho la reina de Inglaterra, juzgando que sus compromisos ya se veían satisfechos con la promesa que he hecho de conservarles los mismos privilegios que a mis fieles castellanos» (Albareda Salvadó 2010: 352).

38 Según José M. Iñurritegui, «medio año antes de concretarse en forma de decretos, el perfil capital de la Nueva Planta ya se conoce. Incluso el lenguaje, los conceptos con los que se había de tejer aquel par de decretos del verano de 1707, ya se manejan con soltura y naturalidad en el otoño de 1706» (Iñurritegui 2002: 293).

39 «La fisura surgida en la Corona de Castilla entre una parte de la población, por reducida que fuera, y Felipe V, a la que contribuyó, sin duda, la actitud de un sector de la alta nobleza y del clero, se materializará por parte del monarca -y esto mismo acontecerá en los reinos de la Corona de Aragón contra los súbditos leales a la causa borbónica- con el encarcelamiento, destierro y confiscación de las propiedades de los desafectos, incluidas sus familias, expulsadas en ocasiones violentamente, aunque no se hubiera comprobado el delito, pues la mera sospecha, fundada o infundada, de falta de lealtad al rey fue suficiente para que se adoptaran tan drásticas sanciones» (Saavedra Zapater 2000: 478-479). 
Jordi Bermejo Gregorio. Perdón, restitución y teatro musical: Antonio de Zamora y su visión poético-musical de los sublevados españoles durante la Guerra de Sucesión

\section{Bibliografía}

Albareda Salvadó, J. (2010) La Guerra de Sucesión en España (1700-1714), Barcelona, Crítica.

Álvarez y Baena, J. A. (1790) Hijos de Madrid Ilustres, II, Madrid, Benito Cano.

Bermejo Gregorio, J. (2017) «Quinto elemento es amor (1701): el fracaso de la representatividad de las fiestas reales del siglo XVII ante la nueva dinastía», en Ballester Morell, B. / A. Bernat Vistarini, A. / Cull, J. T. (eds.) Encrucijada de la palabra y la imagen simbólicas, Palma de Mallorca, José J. Olañeta/Universitat de les Illes Balears, pp. 91-105.

Castro, C. (2004) A la sombra de Felipe V. José de Grimaldo, ministro responsable (1703-1726), Madrid, Marcial Pons.

Covarrubias, S. (1611) Tesoro de la lengua castellana, Madrid, Luis Sánchez.

Flórez Asensio, M. A. (2006) Música teatral en el Madrid de los Austrias durante el Siglo de Oro, Madrid, ICCMU.

Gadamer, H.-G. (1977) Verdad y Método I. Fundamentos de una hermenéutica filosófica, Salamanca, Sígueme.

González Roncero, M. I. (2011) "Las zarzuelas de Antonio de Zamora: índice y comentario", Dieciocho: Hispanic enlightenment, 34, 1, pp. 127-162.

Guillamón, F. J., \& Muñoz, J. (2006) "La lealtad castellana en la Guerra de Sucesión. Movilización social, representación del poder en una sociedad en guerra", Anales de la Universidad de Alicante. Historia Moderna, 24, pp. 513-535.

Iñurritegui Rodríguez, J. M. (2002) “1707: la fidelidad y los derechos”, en Fernández Albaladejo, P. (ed.) Los Borbones. Dinastía y memoria de nación en la España del siglo XVIII, Madrid, Marcial Pons, pp. 245-302.

Kamen, H. (2010) Felipe V. El rey que reinó dos veces, Madrid, Planeta.

Linde Paniagua, E. (1977) "Amnistía y conflictos sociales en la historia de España", Tiempo de historia, 26, pp. 4-23.

Martín Martínez, R. (2003) El teatro breve de Antonio de Zamora (estudio y edición), tesis doctoral inédita por la Universidad Complutense de Madrid bajo la dirección de Javier Huerta Calvo, Madrid.

- (ed.) (2005) Zamora, A., Teatro breve (Entremeses), Madrid/Frankfurt, Iberoamericana/ Vervuert.

Pelliccia, C. (2016) "El regalo de cantatas para el marqués de Aytona y su valor diplomático en la corte de Nápoles (1688-1690)", en Carrió-Invernizzi, D. (dir.) Embajadores culturales. Transferencias y lealtades de la diplomacia española de la Edad Moderna, Madrid, UNED, pp. 321-344.

Sanz Ayán, C. (ed.) (1998) Portocarrero y Guzmán, P., Teatro monárquico de España, Madrid, BOE/ Centro de Estudios Políticos y Constitucionales. 
Jordi Bermejo Gregorio. Perdón, restitución y teatro musical: Antonio de Zamora y su visión poético-musical de los sublevados españoles durante la Guerra de Sucesión

Saavedra Zapater, J. C. (2000) "Entre el castigo y el perdón. Felipe V y los austracistas de la Corona de Castilla, 1706-1705”, Espacio, Tiempo y Forma. Serie IV. Ha Moderna, 13, pp. 469-503.

Valbuena Briones, Á. (ed.) (1969) Calderón de la Barca, P., Obras Completas. Dramas, I, Madrid, Aguilar.

Zamora, A. (1706) Epinicio métrico, prosphonema numeroso, en que explica su júbilo el reverente afecto de la corte, en la deseada feliz restitución a ella de su monarca don Philipo Quinto a quien bumillado le consagra por mano del Señor Don Juan Claros Alonso, Madrid, Agustín Fernández.

- (1722) Comedias nuevas, con los mismos sainetes con que se ejecutaron, asi en el Coliseo del Sitio Real del Buen-Retiro, como en el Salón de Palacio y Teatros de Madrid, Madrid, Diego Martínez Abad.

—. (1741) Obras cómicas de Antonio Várquez de Zamora, [s. 1.] (BNE: MSS/14771).

- (1744) Comedias de Antonio de Zamora, gentil-hombre que fue de la Casa de Su Majestady su oficial de la Secretaría de las Indias, Parte de Nueva España. Dedicadas a su autor, II, Madrid, Joaquín Sánchez. 